\title{
Outflow Obstruction in Takotsubo Cardiomyopathy
}

\section{Simoglou $\mathbf{C}^{* *}$ and Gymnopoulos $\mathrm{D}^{2}$}

${ }^{1}$ Department of Cardiothoracic Surgery, University

Hospital of Evros, Greece

${ }^{2}$ Department of Cardiothoracic Surgery Private Clinic St. Luke's Hospital,Thessaloniki, Greece

*Corresponding author: Simoglou C, Department of Cardiothoracic Surgery, University Hospital of Evros, Greece

Received: February 16, 2018; Accepted: June 05, 2018; Published: June 21, 2018

\section{Abstract}

Takotsudo cardiomyopathy (TCM) is a transient cardiac syndrome that involves left ventricular apical akinesis and mimics acute coronary syndrome. It was first described in Japan in 1990 by sato et al. We report a 77- years old female without known history of coronary artery disease was admitted to emergency department with complaining of rapid onset of severe chest pain after an argument with her family.

Keywords: Takotsudo cardiomyopathy; Coronary disease; Electrocardiogram; Risk factor

\section{Inroduction}

Stress cardiomyopathy, also called apical ballooning syndrome, broken heart syndrome, takotsubo cardiomyopathy (TCM), and stress-induced cardiomyopathy, is an increasingly reported syndrome generally characterized by transient systolic dysfunction of the apical and/or mid segments of the left ventricle (LV) that mimics acute myocardial infarction (AMI), but in the absence of obstructive coronary artery disease [1]. Patients who are in shock should undergo urgent echocardiography to determine if left ventricular outflow tract (LVOT) obstruction is present. In patients with hypotension and severe moderate-severe left LVOT obstruction, inotropic agents should be avoided, because they can worsen the degree of obstruction.

\section{Case Report}

A 77-years-old female without known history of coronary artery disease was admitted to emergency department with complaining of rapid onset of severe chest pain after an argument with her family. The character of the pain was retrosternal squeezing sensation and radiating to jaw and left shoulder. In medical history, she had not a traditional risk factor for coronary artery disease. Her electrocardiogram (ECG) showed ST segment elevations in leads V1-6, II, III, aVF that was consistent with AMI (Figure 1). Due to severe hypotension $(73 / 45 \mathrm{~mm} \mathrm{Hg}$ via intra-arterial measurement) dopamine infusion was started considering of cardiogenic shock and noradrenaline infusion was added because of resistant hypotension. Her coronary angiogram revealed patent coronary arteries with minor irregularities and TIMI-III flow. Transthoracic echocardiography (TTE) showed hypokinesis of apical mid-ventricular walls and a left ventricular ejection fraction of $30 \%$ that was consistent with TCM. Systolic anterior motion of the mitral valve and moderate mitral regurgitation were obtained. The echo-derived peak and mean LVOT gradient was $137 / 61 \mathrm{mmHg}$ respectively (Figure 2). After obtaining of the dynamical LVOT obstruction, inotropic agents were stopped and $500 \mathrm{cc}$ bolus of \%0.9 $\mathrm{NaCI}$ and $5 \mathrm{mg}$ bolus of intravenous (IV) metoprolol treatment were given by reason of deterioration of hemodynamic status. After a while the patient's tachycardia and hypotension was decreased. Oral metoprolol treatment was initiated. The patient's subsequent course was uneventful. A repeat TTE after 3 days showed no LVOT gradient but apical hypokinesis.

\section{Discussion}

Stress cardiomyopathy was first described in Japan [1]. The term "takotsubo" is taken from the Japanese name for an octopus trap, which has a shape that is similar to the apical ballooning configuration of the LV in systole in the typical form of this disorder. In the most
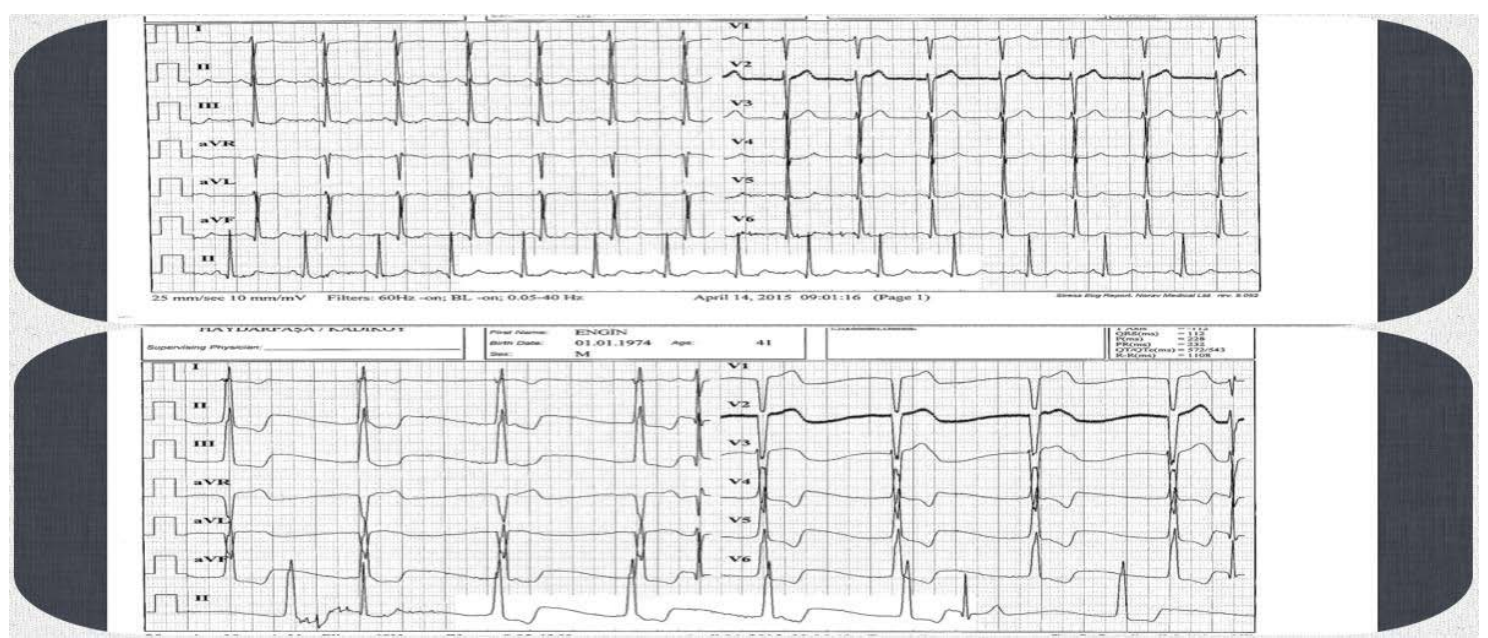

Figure 1: Electrocardiografic changes (Takotsubo cardiomyopathy)

Austin J Clin Case Rep - Volume 5 Issue 2 - 2018 ISSN : 2381-912X | www.austinpublishing group.com Simoglou et al. (@) All rights are reserved
Citation: Simoglou C and Gymnopoulos D. Outflow Obstruction in Takotsubo Cardiomyopathy. Austin J Clin Case Rep. 2018; 5(2): 1131 


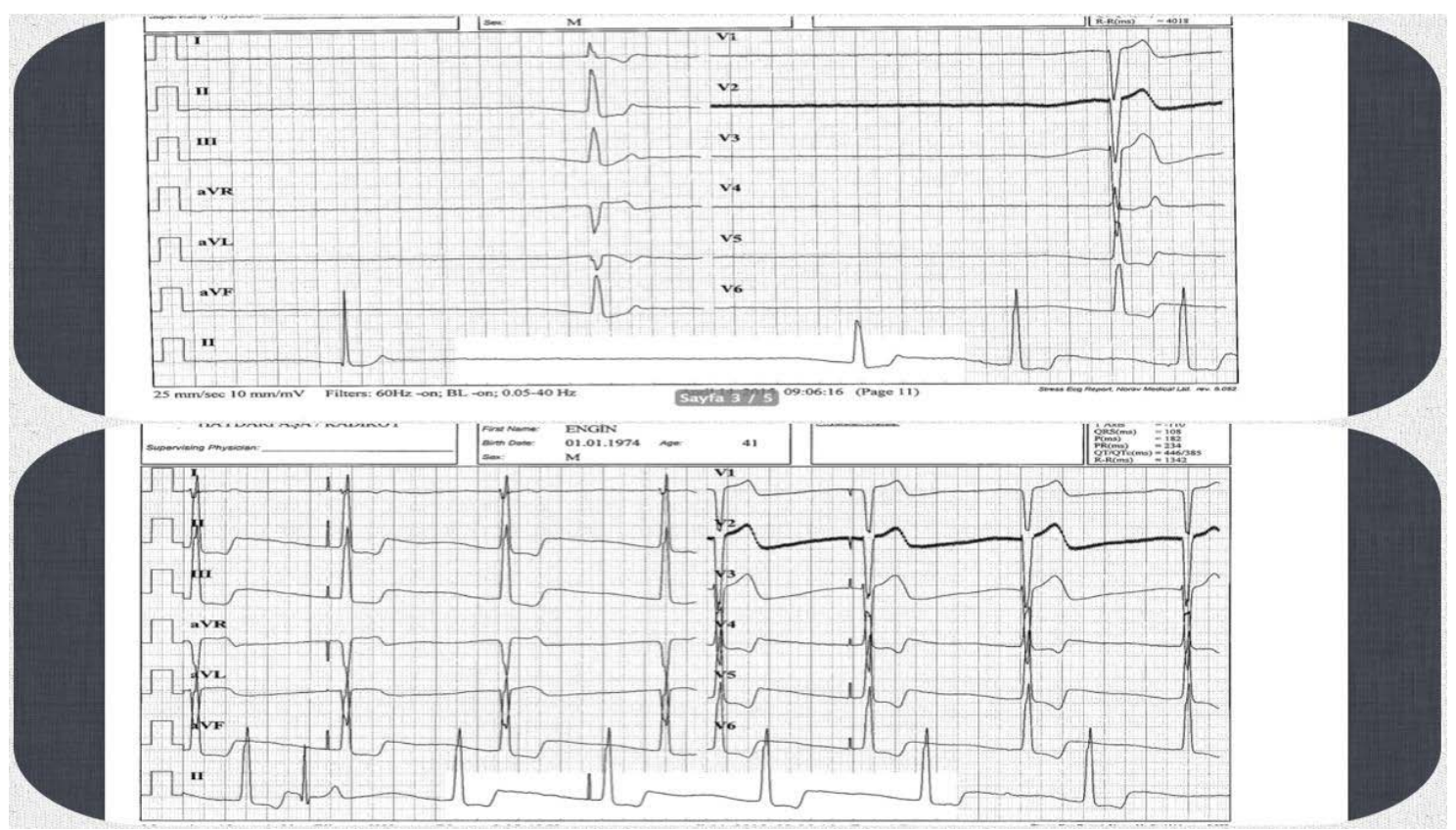

Figure 2: Electrocardiografic changes (Takotsubo cardiomyopathy).

commonly described typical type of stress cardiomyopathy, the contractile function of the mid and apical segments of the LV are depressed, and there is hyperkinesis of the basal walls, producing a balloon-like appearance of the distal ventricle with systole [2].

Once the diagnosis of stress cardiomyopathy has been made, therapy is based upon the patient's overall clinical condition. Patients who are in shock should undergo urgent echocardiography to determine if LVOT obstruction is present. In contrast to hypotension due only to pump failure, hypotension associated with LVOT obstruction should not be treated with inotropic agents, because they can worsen the degree of obstruction. The recommended approach to patients with moderate-to-severe LVOT obstruction includes the use of beta blockers, which can improve hemodynamics by causing resolution of the obstruction. In addition, in the absence of significant pulmonary congestion, the patient should be fluid resuscitated $[3,4]$.

In patients with LVOT obstruction and severe hypotension that either do not tolerate or do not adequately respond to beta blockers, an alpha agonist may be added with caution and close monitoring. Phenylephrine is a pure alpha-adrenergic agonist that may reduce the gradient by increasing after load, thereby improving overall hemodynamics. This treatment may be helpful to support blood pressure while a beta blocker is administered to reduce inotropy. However we did not use a pure alpha agonist, the patient made a good response to serum fluid and IV beta blocker treatment.

*The authors declare that they have no commercial associations or sources of support that might pose a conflict of interest.

\section{References}

1. Sato H, Taiteishi H, Uchida T. Takotsubo-type cardiomyopathy due to multivessel spasm. In: Clinical aspect of myocardial injury: From ischemia to heart failure, Kodama K, Haze K, Hon M (Eds), Kagakuhyouronsha, Tokyo, 56. 1990.

2. Eitel I, von Knobelsdorff-Brenkenhoff F, Bernhardt P, Carbone I, Muellerleile $\mathrm{K}$, Aldrovandi $\mathrm{A}$, et al. Clinical characteristics and cardiovascular magnetic resonance findings in stress (takotsubo) cardiomyopathy. JAMA. 2011; 306: 277.

3. Bybee KA, Kara T, Prasad A. Systematic review: transient left ventricular apical ballooning: a syndrome that mimics ST-segment elevation myocardial infarction. Ann Intern Med. 2004; 141: 858.

4. Tsuchihashi K, Ueshima K, Uchida T, Oh-mura N, Kimura K, Owa M, et al. Transient left ventricular apical ballooning without coronary artery stenosis: a novel heart syndrome mimicking acute myocardial infarction. Angina Pectoris Myocardial Infarction Investigations in Japan. J Am Coll Cardiol. 2001; 38: $11-18$.
Austin J Clin Case Rep - Volume 5 Issue 2 - 2018 ISSN : 2381-912X | www.austinpublishing group.com Simoglou et al. @ All rights are reserved
Citation: Simoglou C and Gymnopoulos D. Outflow Obstruction in Takotsubo Cardiomyopathy. Austin J Clin Case Rep. 2018; 5(2): 1131. 